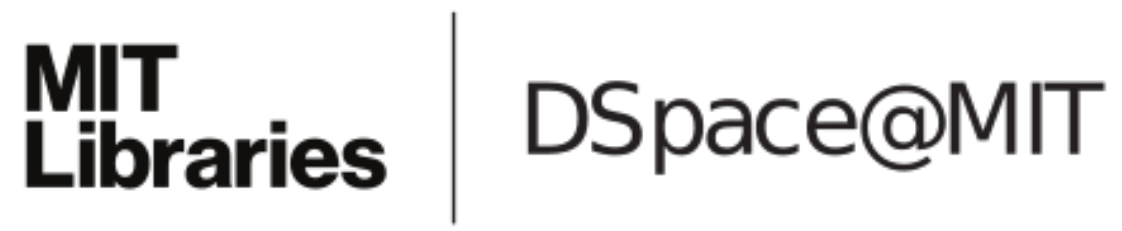

\author{
MIT Open Access Articles
}

Modeling of Travel Time Variations on Urban Links in London

The MIT Faculty has made this article openly available. Please share how this access benefits you. Your story matters.

Citation: Hasan, Samiul, Charisma F. Choudhury, Moshe E. Ben-Akiva, and Andy Emmonds. "Modeling of Travel Time Variations on Urban Links in London." Transportation Research Record: Journal of the Transportation Research Board 2260, no. 1 (December 1, 2011): 1-7.

As Published: http://dx.doi.org/10.3141/2260-01

Publisher: Transportation Research Board of the National Academies

Persistent URL: http://hdl.handle.net/1721.1/89071

Version: Final published version: final published article, as it appeared in a journal, conference proceedings, or other formally published context

Terms of Use: Article is made available in accordance with the publisher's policy and may be subject to US copyright law. Please refer to the publisher's site for terms of use. 


\title{
Modeling of Travel Time Variations on Urban Links in London
}

\author{
Samiul Hasan, Charisma F. Choudhury, Moshe E. Ben-Akiva, \\ and Andy Emmonds
}

\begin{abstract}
An econometric framework was developed to combine data from various sources to identify the key factors contributing to travel time variations in Central London. Nonlinear latent variable regression models that explicitly accounted for measurement errors in the data were developed to combine data extracted from automatic number plate recognition cameras and automatic traffic counters. This procedure significantly differed from previous research in this area that was based primarily on traffic flow data and ignored measurement errors. The results indicate that nonlinear latent variable regression models can effectively explain travel time variations on a regular day by using variables related to vehicle type, traffic density, and traffic composition. Test results indicate that the proposed framework for correcting measurement errors yields significant improvements over base models, where such errors are ignored. The findings from the study validate some key hypotheses regarding influences of various factors on speed of urban traffic streams and can serve as a tool for investigation of the causes of traffic congestion. The model framework is general enough for application in other cases in which traffic data have similar measurement errors.
\end{abstract}

With the rapid increase in travel demands and constraints in resources to proportionately increase the supply, traffic congestion and delay have become unavoidable attributes of most of the major cities in the world. The relationship among demand, supply, and congestion level is complex $(1,2)$. For instance, traffic surveys show that in recent years, there has been a decline in travel demand in Central London in response to charges for congestion but a decline in speeds and an increase in congestion (3). The decline in speed has been attributed to various factors likely to affect the effective capacity, which ranged from reduction of the physical capacity to accommodate more bus lanes to lengthening of pedestrian phases in traffic signals. However, it is not clear how each of the factors affecting demand and supply contributed to increases or decreases in travel times.

Accurate predictions of travel times are important for transportation planning, as well as for operations of traffic management centers

S. Hasan, School of Civil Engineering, Purdue University, 550 Stadium Mall Drive, West Lafayette, IN 47907. C. F. Choudhury, Department of Civil Engineering, Bangladesh University of Engineering and Technology, Dhaka 1000, Bangladesh. M. E. Ben-Akiva, Department of Civil and Environmental Engineering, Massachusetts Institute of Technology, Suite 1-181, 77 Massachusetts Avenue, Cambridge, MA 02139. A. Emmonds, Network Performance, Traffic Directorate, Transport for London, 197 Blackfriars Road, London SE1 8NJ, United Kingdom. Corresponding author: C. F. Choudhury, cfc@alum.mit.edu.

Transportation Research Record: Journal of the Transportation Research Board, No. 2260, Transportation Research Board of the National Academies, Washington,

D.C., 2011, pp. 1-7.

DOI: 10.3141/2260-01 and traveler information systems. The practical importance of the research to model travel time variations in urban links has prompted increased research interest in investigating how the demand and supply parameters affect the speed and travel time variations. This has been fostered in recent years by the relative ease of nonintrusive data collection technologies that use a variety of sources, including automatic traffic counters (ATC), automatic number plate readers (ANPR), and vehicles equipped with the Global Positioning System and smartphone devices. Modeling travel time variations in the urban environment is much more challenging than that of freeways because of the more complex network topologies, greater heterogeneity of the vehicle fleet, effects of pedestrian and parking activities, increased frequency of traffic control measures, and so forth.

The simplest category of models of travel time variations for urban links select a probability distribution function and calibrate the parameters associated with the distribution such that it best fits the available data (4-6). Most of these models make use of data from loop detectors and deal with the additional complexity of inferring the travel times from the detector data. Commonly used methods of such inference include use of the speed-flow-density relationships (7-11), correlation analysis (12), platoon identification (13), dynamic input-output (14), and pattern recognition (15). These models mostly consider the effects of traffic characteristics on travel time, and the causal relationships between travel times and roadway attributes are ignored.

A second category of models focus on estimating the expected travel time over a link in the period of interest by using inputs such as static variables (e.g., road width, number of lanes, number of signals) or dynamic traffic characteristics (e.g., flow, occupancy). Sisiopiku et al. (16) and Sisiopiku and Rouphail (17) examined the use of detector output from simulation and field studies to improve the performance of arterial travel time estimation. They found that regression equations can be fitted for certain ranges of occupancies to model the observed relationships between arterial through travel time and detector occupancy. Turner et al. developed regression models to predict travel times on freeways and urban links where travel times in urban links were found to linearly vary with demand and spacing of traffic signals (18). Zhang modeled travel times as a linear combination of occupancy, flow, and signal parameters (19). An improved speed-flow relationship was developed by Skabardonis and Dowling (20) and was shown to be effective in calculating arterial link travel times (21). Xie et al. treated arterial link travel time as the summation of cruise time and signal delay estimated with a simplified intersection queuing diagram (22). Travel time models based on queuing theory were also developed by Young (23). Stephanopoulos and Michalopoulos developed a relationship between interrupted and uninterrupted speed with detector data based on shockwave 
theory (24), which was later enhanced by Pueboobpaphan et al. by combining probe vehicle data with detector data (25). Ruiz Juri et al. presented an approach of combining statistical forecasting techniques with traffic simulation for online short-term prediction of point-to-point freeway travel time (26).

In another variation of the travel time estimation model, the travel time for each individual vehicle traveling on a link is estimated. Use of these models requires consideration of factors such as individual vehicle characteristics, traffic light offsets, traffic density or volume, and position of vehicle in platoon. Robinson (27) and Robinson and Polak (28) developed a model for estimation of travel time on urban links that was based on the $k$ nearest neighbors method. This method estimates the travel time of an individual vehicle by using its features and the corresponding features of a particular number of its closest neighbors from a historical database. Although such a nonparametric method is useful for operational purposes, it provides little insight into the causal relationship between the network and traffic characteristics and the travel time.

Neural networks have been used to develop models for travel time prediction $(29,30)$. These methods require the appropriate selection of training data sets so that extensive training of the neural network models can be conducted. Also, they lack transparency, which makes it difficult to gain useful insight into the factors giving rise to variability in travel times. In addition, the literature suggests that more research is needed to optimize the architecture of the neural network for use in estimating travel times in urban links (28).

The preceding research focused primarily on recurrent delay. To model effects of incidents on travel time, Fu and Rilett used statistical distributions for incidents in dynamic stochastic networks (31). Hobeika and Dhulipala developed a rule-based model in which incident type and severity and vehicle type were used to estimate the range of time needed for traffic to reach normalcy (32). These models, however, needed very detailed incident data and ignored variations caused by recurrent delay.

This paper develops a framework to combine data from various sources (which have varying levels of errors) and perform econometric analysis to determine how factors contribute to travel time variations in Central London. A model framework is sought that will help Transport for London (TfL) quantify the share of delays caused by various roadway and traffic factors.

\section{BACKGROUND AND DATA}

Charging for congestion was introduced in London to reduce traffic congestion and make journeys quicker by encouraging people to choose other forms of transport. According to the sixth annual impacts monitoring report on Central London congestion charging (3), in the 2 years immediately following the introduction of the original scheme (2003 and 2004), there was a 30\% reduction in congestion from the 2002 baseline. Further, the level of traffic for all vehicle types entering the central congestion charge zone was consistently $16 \%$ lower in 2006 than the precharge levels in 2002 (Figure 1). The congestion charge brought in an annual operating net income of $£ 89.1$ million for TfL during FY 2006-2007 (33).

However, recent measurements of congestion have indicated that conditions are deteriorating. Data from the monitoring program for congestion charging in Central London indicate a substantial loss of charging-related decongestion benefits in the past 18 months within the original charging zone. As shown in Figure 2, the average reduction in congestion for the 2005 calendar year was $22 \%$, lower than 2003 and 2004; in 2006 and 2007, there was an accelerating loss of the original congestion benefits. Average congestion in 2006 was just $8 \%$ below precharging levels. Average congestion in 2007 was identical to representative precharging values. This is despite sustained reduction in the volume of traffic circulating within the original charging zone (3).

Because of the failure to reduce delays commensurate to reductions in traffic flow, a detailed analysis is needed that explores the causes of delay. In the current research, econometric models are developed to quantify how various factors contribute to fluctuations in speed and lead to variations in travel time.

The analysis was aided by extensive data from the ANPR cameras in the congestion charging zone. Central London has a good coverage of other data collection mechanisms as well. The available data sources from the congestion charging zone include the following:

1. ANPR camera data,

2. ATC traffic flow,

3. Cycle flow (in some parts of the zone),

4. London Traffic Information System incident data,

5. Split-cycle offset optimization technique (SCOOT) flow, and

6. Configuration of bus lane.

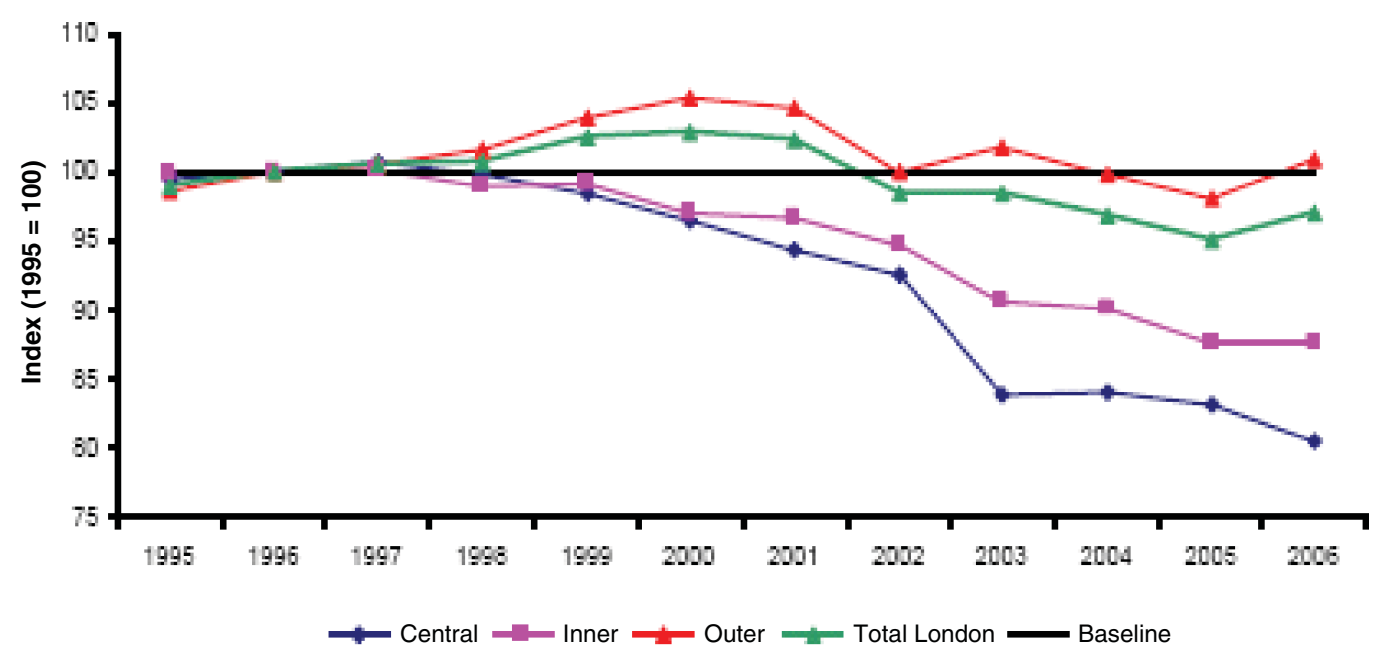

FIGURE 1 Average weekday 12-h (7:00 a.m. to 7:00 p.m.) traffic flow per kilometer on major roads (3). 


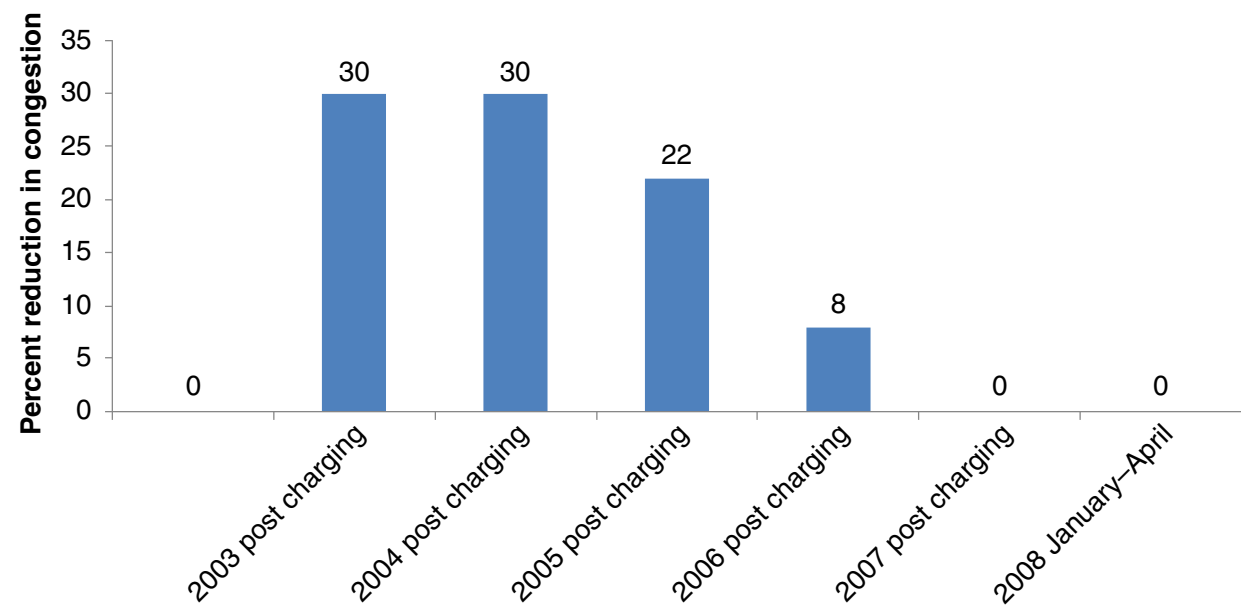

FIGURE 2 Comparative congestion statistics for Central London charging zone. Congestion is measured as average excess delay in minutes per kilometer based on moving car observer speed survey (3).

ANPR and ATC data were used for the model estimation in this research. ANPR data from a particular camera pair reports the travel time of individual vehicles that travel between the camera pair. No incident occurrence was found in the respective days of available ANPR data. Some signal cycle length data are available, but these are very aggregate measurement of the cycle lengths (i.e., average over few days). In models of individual links, the presence of a bus lane is not a suitable variable for the model. If multiple links are modeled together, it can be used as an independent variable.

\section{MODEL STRUCTURE}

In this study, a latent variable regression model was developed that considered individual vehicle speed as the dependent variable. The candidate variables likely to influence the speed of a vehicle include road network characteristics (e.g., number of lanes, lane widths, presence of bus lanes), traffic characteristics like traffic density, traffic mix (e.g., proportion of buses, minibuses, taxis), and types of subject vehicle (e.g., car, bus). Within the study network, the number of lanes, lane widths, and other geometric characteristics remain unchanged. The traffic-related variables are derived from ANPR and ATC data. The ANPR data are used to calculate traffic densities, traffic volume, and proportion of kinds of vehicles (i.e., traffic mix). ATC data are used to obtain the traffic volumes. However, comparison of traffic volume from ANPR and ATC reveal some inconsistencies. It is assumed that two sources of errors may have contributed to the inconsistency present in the ANPR data: omitting the observations with origin destinations different than the ANPR link pair and incorrect reporting of numbers of vehicles in high congestion.

The first error occurs if a vehicle is captured in the first ANPR camera but not in the second ANPR camera. Therefore, vehicles that are taking a turn or that have both origins and destinations within the ANPR camera pairs are not recorded in the ANPR database. The second error occurs because in high congestion, ANPR often does not record all vehicles. The ANPR traffic densities therefore underrepresent the true density of the road and, because of the nature of the errors, simple methods like use of a constant scaling factor are not usable for correcting the errors. In the proposed model, the true density is therefore considered to be a latent (i.e., unobserved) variable. An alternate indication of density can be derived from the ATC traffic flow data. However, these data can also have measurement errors, the extent of which is unknown.

Given these data limitations, a structural and measurement equation modeling approach was adopted for modeling an individual vehicle's speed. This modeling approach, although common in psychology (34), marketing (35), and travel demand modeling (36-39), has not been used previously in traffic modeling.

The general model framework proposed in this research is an application of the structural and measurement equation modeling, shown in Figure 3. The equation capturing the relationship between individual vehicle speed and explanatory variables (including latent traffic density) (Equation 1) constitutes the structural model, whereas the relationships between ATC traffic flow and latent traffic density and ANPR density and latent traffic density (Equation 2) constitute the measurement model.

Structural model:

speed $=\boldsymbol{\beta}^{\prime} \boldsymbol{X}+\gamma d+\boldsymbol{\epsilon}$

where

$\boldsymbol{X}=$ vector of explanatory variables,

$\boldsymbol{\beta}=$ vector of estimable parameters or coefficients,

$d=$ latent (i.e., unobserved) traffic density of the road,

$\gamma=$ parameter for traffic density, and

$\epsilon=$ random error term.

Measurement model:

ANPR density $=\lambda_{1} d+\varphi$

ATC traffic flow (for free-flow part) $=\lambda_{2} d+\omega$

ATC traffic flow (for congested part) $=\alpha+\lambda_{3} d+v$

where $\alpha, \lambda_{1}, \lambda_{2}$ and $\lambda_{3}$ are estimable parameters and $\varphi, \omega$, and $v$ are random error terms. 


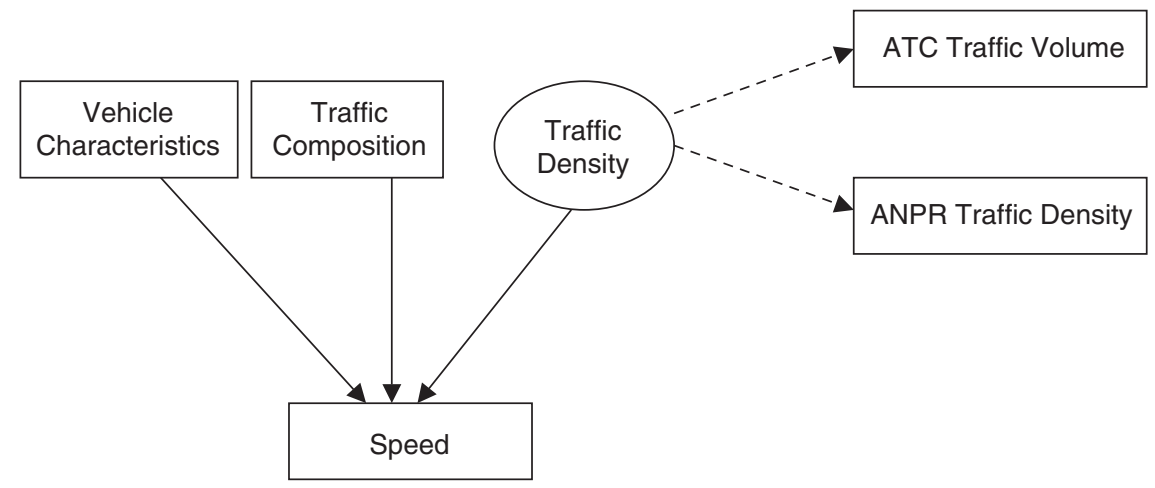

FIGURE 3 Latent variable model structure. Observed variables are shown in rectangles; traffic density is an unobserved variable.

Vehicle characteristics considered in the model (Figure 3) represent the type of vehicle [e.g., heavy-goods vehicle (HGV), light-goods vehicle (LGV), bus, taxi]. Traffic composition represents the proportion of vehicle types in the traffic stream (e.g., HGV, LGV, bus, taxi). These traffic composition variables are calculated as the ratio between the numbers of vehicles for a specific type to the total number of vehicles obtained from ANPR data. This is not fully accurate because ANPR data might omit vehicles as discussed earlier; however, they are used in this model because there are no other indicators of vehicle composition. Moreover, it can be assumed that the ANPR data omissions are random (i.e., not specific to any particular vehicle type), and therefore missing observations do not substantially influence the vehicle compositions.

The relationship between ATC traffic flow and the latent traffic density (as expressed in Equation 2) will be nonlinear. The relationship between traffic flow and traffic density reported in existing literature is used, as is a slightly modified form of the following density and flow relationship for urban street developed by Leclercq (40). For free-flow regime $\left(k \leq k_{c}\right)$, flow

$q=a k^{2}+b k$

For congested-flow regime $\left(k>k_{c}\right)$,

$q=c+d k$

where

$$
\begin{aligned}
k_{c} & =\text { critical traffic density } \\
k & =\text { traffic density, and } \\
a, b, c, d & =\text { model parameters. }
\end{aligned}
$$

According to this relationship, there are two regimes, free-flow and congested, the first having a nonlinear and a linear part. However, the first part of Equation 3 was simplified because the ability of the estimation procedure to handle nonlinear terms was limited. The density-flow relationship therefore reduces to the following. For free-flow regime $\left(k \leq k_{c}\right)$, flow

$q=b k$

For congested-flow regime $\left(k>k_{c}\right)$,

$q=c+d k$

where $k_{c}$ is the critical traffic density determined from plotting the data.

During estimation, the data is therefore grouped into two parts, free-flow and congested, and parameters for two density-flow equa- tions are estimated with the other model parameters. The parameters for structural equations remain same for two groups.

\section{RESULTS}

The preceding latent variable modeling approach was adopted to build a model for individual vehicle speed using the data from a street (Gower Street) in London. The ANPR data and ATC data for a typical work day (May 16, 2008) were collected and used for the model estimation. The estimation results of the best model specification (Equation 1) for Gower Street are given in Table 1. Model 1 assumes that ANPR density has measurement errors, and Model 2 assumes that ANPR density is error free. The parameter estimates obtained from both models are very close to their values. A statistical test was then used to determine if these differences are statistically significant.

Results show that all the explanatory variables except Dummy HGV and Dummy LGV are statistically insignificant at the .05 significance level. However, these variables are retained in the model specification so that the coefficients of the other dummy and proportion variables can be interpreted. All the variables have plausible signs.

The intercept of the model represents the average free-flow speed of a passenger car in the street. From the value of this intercept, it can be interpreted that the average free-flow speed of a passenger car for Gower Street is about $21 \mathrm{~km} / \mathrm{h}$. Similarly, for this street, the average free-flow speeds of HGV, LGV, taxi, and bus can be calculated by adding the corresponding with the intercept. The lowest free-flow speed for buses reflects the presence of several bus stops along Gower Street. Taxis in this street have a slightly greater free-flow speed than that of buses.

Results also indicate that traffic density has a significant negative influence on individual vehicle speed. Taxi proportions and bus proportions have negative a impact on individual vehicle speed. This finding reflects the greater level of bus and taxi movements in Gower Street and its associated effects on vehicle speed. HGV proportion has a positive impact on vehicle speed; however, this counterintuitive fact is probably explained by the very low $\mathrm{HGV}$ proportion present in Gower Street (average HGV proportion is $1.88 \%$ ).

Overall, the model gives satisfactory results for predicting individual vehicle speed for an urban street. It shows some interesting effects of vehicle types and their proportions in traffic mix on vehicle speed. The model is also suitable compared with other speed (or travel time) prediction methods, because it provides better insights on the relative influences of different factors on vehicle speed. These insights, as well as the empirical relationships found in the model, can benefit urban traffic operations and management. 


\begin{tabular}{|c|c|c|c|c|c|c|}
\hline \multirow[b]{2}{*}{ Variable Description } & \multicolumn{3}{|c|}{$\begin{array}{l}\text { Assuming Measurement Error } \\
\text { in ANPR Density }\end{array}$} & \multicolumn{3}{|c|}{$\begin{array}{l}\text { Assuming No Measurement Error } \\
\text { in ANPR Density }\end{array}$} \\
\hline & Coefficient & $\begin{array}{l}\text { Standard } \\
\text { Error }\end{array}$ & $t$-Statistic & Coefficient & $\begin{array}{l}\text { Standard } \\
\text { Error }\end{array}$ & $t$-Statistic \\
\hline Intercept & 20.6235 & 0.4888 & 42.1932 & 20.4829 & 0.4868 & 42.0723 \\
\hline Dummy HGV 1 if the vehicle is an HGV-type vehicle, 0 otherwise & -1.2128 & 0.9297 & -1.3046 & -1.1945 & 0.9316 & -1.2822 \\
\hline Dummy LGV 1 if the vehicle is an LGV-type vehicle, 0 otherwise & -1.0203 & 0.6423 & -1.5886 & -1.0227 & 0.6438 & -1.5887 \\
\hline Dummy taxi 1 if the vehicle is a taxi, 0 otherwise & -1.9031 & 0.5741 & -3.3151 & -1.8876 & 0.5753 & -3.2811 \\
\hline Dummy bus 1 if the vehicle is a bus, 0 otherwise & -2.9960 & 0.3796 & -7.8915 & -2.9960 & 0.3813 & -7.8566 \\
\hline Traffic density (vehicles/km) & -2.6984 & 0.1520 & -17.7474 & -2.2373 & 0.1366 & -16.3796 \\
\hline HGV proportion & 4.2460 & 1.0281 & 4.1301 & 4.1322 & 1.0196 & 4.0526 \\
\hline Taxi proportion & -1.6868 & 0.8012 & -2.1054 & -1.7491 & 0.8021 & -2.1805 \\
\hline Bus proportion & -1.4066 & 0.5542 & -2.1054 & -1.4928 & 0.5551 & -2.6894 \\
\hline Number of observations & & & 563 & & & 563 \\
\hline Goodness-of-fit index (GFI) & & & 0.9711 & & & 0.9706 \\
\hline Adjusted GFI (AGFI) & & & 0.9225 & & & 0.9236 \\
\hline
\end{tabular}

Note: Results are based on latent variable model specification. HGV = heavy goods vehicle, LGV = light goods vehicle.

\section{MODEL SPECIFICATION TEST}

This section presents a statistical test for evaluating the specification of the model. The Hausman specification test is used for this purpose (41). The Hausman specification test is a classical test of whether a particular model specification should be used. The question is whether there is significant measurement error in the ANPR data (i.e., the density calculated from ANPR data has errors). If ANPR data do not have any measurement errors, the model with ANPR density as an explanatory variable may be more powerful and parsimonious. However, if ANPR density data have measurement errors, then the parameters from this model will be inconsistent, and a model with measurement equations for ANPR densities will be preferable (i.e., treating density as a latent variable).

The null hypothesis for the test is that there is no measurement error in ANPR data. Under this hypothesis, the parameter estimates from the original model will be consistent. Here the original model is estimated restricting the coefficient of density equal to 1 (i.e., $\lambda_{1}=1$ in Equation 2). Let the vector of estimated parameters from this model be $\widehat{\boldsymbol{\beta}_{0}}$ and the variance-covariance matrix of the estimated parameters be $\operatorname{Var}\left(\widehat{\boldsymbol{\beta}_{0}}\right)$. Under the alternate hypothesis of the presence of measurement error in ANPR data, the parameter estimates from the model with measurement equation (i.e., $\lambda_{1}$ is free in Equation 2) will also be consistent but more efficient. Let the vector of estimated parameters from this model be $\widehat{\boldsymbol{\beta}_{1}}$ and the variance-covariance matrix of the estimated parameters be $\operatorname{Var}\left(\widehat{\boldsymbol{\beta}_{1}}\right)$. Then the Hausman test statistic can be defined as

$m=\left(\widehat{\boldsymbol{\beta}_{0}}-\widehat{\boldsymbol{\beta}_{1}}\right)^{\prime}\left(\operatorname{Var}\left(\widehat{\boldsymbol{\beta}_{0}}\right)-\operatorname{Var}\left(\widehat{\boldsymbol{\beta}_{1}}\right)\right)^{-1}\left(\widehat{\boldsymbol{\beta}_{0}}-\widehat{\boldsymbol{\beta}_{1}}\right)$

This test statistic is asymptotically distributed as $\chi^{2}$ with degrees of freedom equal to the number of parameters in the model estimated with no measurement error in the ANPR data. The test statistic is obtained as $m=70.12$ with degrees of freedom equal to 9 . Because $\chi_{9}^{2}$ has a critical value of 21.67 at the .01 significance level, the null hypothesis of no measurement error in ANPR data can be rejected.
This also provides strong evidence of the presence of error in the ANPR data. Therefore, the model, with structural and measurement equations, presented here is more preferable than a model that includes ANPR density, assuming that it has no measurement error.

\section{MODEL VALIDATION}

To validate the test of the model, the ANPR and ATC data are used for the same road for a different date (May 15, 2008). The test involves estimation of two models. Model 1 uses the coefficients of the model estimated on the May 16 data. Here the model is estimated with the data of May 15 but with the coefficients restricted to be equal to those found in Table 1 (coefficients of the model with measurement error). Model 2 estimates the same model by using the data of May 15 without restricting the coefficients. The comparisons of the goodness-of-fit statistics between two models are as follows:

$\begin{array}{lcc}\begin{array}{l}\text { Goodness-of-Fit } \\ \text { Measure }\end{array} & \begin{array}{l}\text { Model 1 } \\ \text { (restricted model) }\end{array} & \begin{array}{l}\text { Model 2 } \\ \text { (unrestricted model) }\end{array} \\ \text { GFI } & 0.9696 & 0.9596 \\ \text { AGFI } & 0.9362 & 0.8905\end{array}$

The goodness-of-fit measures suggest a reasonable fit of the proposed model to the data of a different day. However, a rigorous approach of model validation would be to predict the speed for a different day based on its traffic variables. However, this would require extracting the latent traffic density variable for which no straightforward approach exists.

\section{SUMMARY AND CONCLUSIONS}

This paper presented a model for predicting individual vehicle speed to explain the travel time variations for an urban street in London by using data from multiple sources. However, at least one of the data sources (ANPR data) was assumed to have measurement errors (if not both); the model used an approach of structural and 
measurement equations to correct the model estimates. The validity of the proposed modeling approach was demonstrated by use of a statistical test, which confirmed that the presence of measurement errors in the data is statistically significant. The test also established that adopting the proposed approach ensures statistically significant improvements over the base models (where measurement errors are ignored).

The findings provide valuable insights on influences of various factors on urban traffic conditions. Variables such as vehicle type, traffic density, and vehicle proportions were found to influence the traffic speed of a street. In particular, the negative impact of bus proportions and taxi proportions may explain the counterintuitive fact of speed reduction in the congestion charging zone of Central London despite a significant reduction in traffic volume. With the introduction of congestion charging, the number of buses and taxis has increased significantly. As a result, the traffic mixture has changed for the congestion charging zone with increasing proportions of buses and taxis. The increasing proportions of buses and taxis and their corresponding negative impact on speed may explain the reduction of speed. These findings therefore have important implications for urban traffic operations and management.

Although the modeling methodology was developed to address a specific limitation of the available data in a particular case, the model framework is general enough for application in other cases in which traffic data have similar measurement errors. The presented methodology is also useful for combining multiple sources of traffic data.

The study had several limitations, however. For example, travel time in a street having multiple signalized intersections depends on turning movements at intersections and signal timing. These influences were not captured in this study, because it was not possible to extract such information from the available data sources. Availability of detailed trajectory data of all vehicles in a traffic stream could allow inclusion of these variables. Another alternative would be to use the simulation approach to generate the missing turning movement data and then enrich the current models with those data. Such approach will be a focus for future research. The methodology could also be applied in various scenarios with data from other networks and traffic conditions to test if the results can be generalized.

\section{ACKNOWLEDGMENTS}

This research was based on work supported by Transport for London under a joint research program with the Massachusetts Institute of Technology.

\section{REFERENCES}

1. Rhoads, T. A., and J. F. Shogren. Why Do Cities Use Supply Side Strategies to Mitigate Traffic Congestion Externalities? Economics Letters, Vol. 92, 2006, pp. 214-219.

2. Hills, P., J. Schmoecker, T. May, R. Liu, S. Shepherd, J. Bates, and N. Paulley. Analysis of Congested Networks. Department of Transport, United Kingdom, 2005.

3. Central London Congestion Charging: Impacts Monitoring: Sixth Annual Report. Transport for London, 2008.

4. Chelst, K., and J. P. Jarvis. Estimating the Probability Distribution of Travel Times for Urban Emergency Service Systems. Operations Research, Vol. 27, No. 1, 1979, pp. 199-204.

5. Emam, E., and H. Al-Deek. Using Travel Time Data to Develop Statistical Models for Evaluating the Performance of Transportation Facilities.
Presented at 86th Annual Meeting of the Transportation Research Board, Washington, D.C., 2007.

6. Petty, K., P. Bickel, M. Ostland, J. Rice, F. Schoenberg, J. Jiang, and Y. Ritov. Accurate Estimation of Travel Times from Single-Loop Detectors. Transportation Research Part A, Vol. 32, No. 1, 1998, pp. 1-17.

7. Traffic Assignment Manual. Bureau of Public Roads, U.S. Department of Commerce, 1964.

8. Athol, P. Interdependence of Certain Operational Characteristics Within a Moving Traffic Stream. In Highway Research Record 72, HRB, National Research Council, Washington, D.C., 1965, pp. 58-87.

9. Gault, H. E., and I. G. Taylor. The Use of the Output from Vehicle Detectors to Assess Delay in Computer-Controlled Area Traffic Control Systems. Transport Operation Research Group, University of New Castle upon Tyne, Newcastle, United Kingdom, 1977.

10. Hall, F. L., and B. N. Persaud. Evaluation of Speed Estimates Made with Single-Detector Data from Freeway Traffic Management Systems. In Transportation Research Record 1232, TRB, National Research Council, Washington, D.C., 1989, pp. 9-16.

11. Jacobson, L. N., N. L. Nihan, and J. D. Bender. Detecting Erroneous Loop Detector Data in a Freeway Traffic Management System. In Transportation Research Record 1287, TRB, National Research Council, Washington, D.C., 1990, pp. 151-166.

12. Guo, H., and J. Jin. Travel Time Estimation with Correlation Analysis of Single-Loop Detector Data. In Transportation Research Record: Journal of the Transportation Research Board, No. 1968, Transportation Research Board of the National Academies, Washington, D.C., 2006, pp. 10-19.

13. Lucas, D. E., P. B. Mirchandani, and N. Verma. Online Travel Time Estimation Without Vehicle Identification. In Transportation Research Record: Journal of the Transportation Research Board, No. 1867, Transportation Research Board of the National Academies, Washington, D.C., 2004, pp. 193-201.

14. Strobel, H. Traffic Control Systems Analysis by Means of Dynamic State and Input-Output Models. International Institute of Applied Systems Analysis, Laxenburg, Austria, 1977.

15. Bohnnke, P., and E. Phannerstill. A System for the Automatic Surveillance of Traffic Situations. ITE Journal, Vol. 56, No. 1, 1986, pp. 41-45

16. Sisiopiku, V. P., N. M. Rouphail, and A. Santiago. Analysis of Correlation Between Arterial Travel Time and Detector Data from Simulation and Field Studies. In Transportation Research Record 1457, TRB, National Research Council, Washington, D.C., 1994, pp. 166-173.

17. Sisiopiku, V. P., and N. M. Rouphail. Toward the Use of Detector Output for Arterial Link Travel Time Estimation: A Literature Review. In Transportation Research Record 1457, TRB, National Research Council, Washington, D.C., 1994, pp. 158-165.

18. Turner, S. M., T. J. Lomax, and H. S. Levinson. Measuring and Estimating Congestion Using Travel Time-Based Procedures. In Transportation Research Record 1564, TRB, National Research Council, Washington, D.C., 1996, pp. 11-19.

19. Zhang, H. M. Link-Journey-Speed Model for Arterial Traffic. In Transportation Research Record: Journal of the Transportation Research Board, No. 1676, TRB, National Research Council, Washington, D.C., 1999, pp. 109-115.

20. Skabardonis, A., and R. Dowling. Improved Speed-Flow Relationships for Planning Applications. In Transportation Research Record 1572, TRB, National Research Council, Washington, D.C., 1997, pp. 18-23.

21. Xiong, H., and G. Davis. Travel Time Estimation on Arterials. Presented at 87th Annual Meeting of the Transportation Research Board, Washington, D.C., 2008.

22. Xie, X., R. L. Cheu, and D. H. Lee. Calibration-Free Arterial Link Speed Estimation Model Using Loop Data. ASCE Journal of Transportation Engineering, Vol. 127, No. 6, 2001, pp. 507-514.

23. Young, C. P. A Relationship Between Vehicle Detector Occupancy and Delay at Signal-Controlled Junctions. Traffic Engineering and Control, Vol. 29, 1988, pp. 131-134.

24. Stephanopoulos, G., and P. G. Michalopoulos. Modelling and Analysis of Traffic Queue Dynamics at Signalized Intersections. Transportation Research Part A, Vol. 13, 1979, pp. 295-307.

25. Pueboobpaphan, R., T. Nakatsuji, H. Suzuki, and A. Kawamura. Transformation Between Uninterrupted and Interrupted Speeds for Urban Road Applications. In Transportation Research Record: Journal of the Transportation Research Board, No. 1934, Transportation Research Board of the National Academies, Washington, D.C., 2005, pp. 72-82.

26. Ruiz Juri, N., A. Unnikrishnan, and S. T. Waller. Integrated Traffic Simulation-Statistical Analysis Framework for Online Prediction of 
Freeway Travel Time. In Transportation Research Record: Journal of the Transportation Research Board, No. 2039, Transportation Research Board of the National Academies, Washington, D.C., 2007, pp. 24-31.

27. Robinson, S. The Development and Application of an Urban Link Travel Time Model Using Data Derived from Inductive Loop Detectors. $\mathrm{PhD}$ thesis. Centre for Transport Studies, Imperial College London, United Kingdom, 2005.

28. Robinson, S., and J. W. Polak. Modeling Urban Link Travel Time with Inductive Loop Detector Data by Using the k-NN Method. In Transportation Research Record: Journal of the Transportation Research Board, No. 1935, Transportation Research Board of the National Academies, Washington, D.C., 2005, pp. 47-56.

29. Liu, H., H. W. C. van Lint, and H. J. van Zuylen. Neural-Network-Based Traffic Flow Model for Urban Arterial Travel Time Prediction. Presented at 86th Annual Meeting of the Transportation Research Board, Washington, D.C., 2007.

30. Wei, C.-H., S.-C. Lin, and Y. Li. Empirical Validation of Freeway Bus Travel Time Forecasting. Transportation Planning Journal, Vol. 32, 2003, pp. 651-679.

31. Fu, L. and L. R. Rilett. Real-Time Estimation of Incident Delay in Dynamic and Stochastic Networks. In Transportation Research Record 1603 TRB, National Research Council, Washington, D.C., 1997, pp. 99-105.

32. Hobeika, A., and S. Dhulipala. Estimation of Travel Times on Urban Freeways Under Incident Conditions. In Transportation Research Record: Journal of the Transportation Research Board, No. 1867, Transportation Research Board of the National Academies, Washington, D.C., 2004, pp. 97-106.

33. Annual Report and Statement of Accounts 2006/07. Transport for London, 2007.

34. Anderson, J. C., and D. W. Gerbing. Structural Equation Modeling in Practice: A Review and Recommended Two-Step Approach. Psychological Bulletin, Vol. 103, No. 3, 1988, pp. 411-423.
35. Bagozzi, R. P., and Y. Yi. On the Evaluation of Structural Equation Models. Journal of the Academy of Marketing Science, Vol. 16, No. 1, 1988, pp. 74-94.

36. Ben-Akiva, M., D. McFadden, K. Train, J. Walker, C. Bhat, M. Bierlaire, D. Bolduc, A. Boersch-Supan, D. Brownstone, D. S. Bunch, A. Daly, A. de Palma, D. Gopinath, A. Karlstrom, and M. A. Munizaga. Hybrid Choice Models: Progress and Challenges. Marketing Letters, Vol. 13, No. 3, 2002, pp. 163-175.

37. Ben-Akiva, M., J. Walker, A. Bernardino, D. Gopinath, T. Morikawa, and A. Polydoropoulou. Integration of Choice and Latent Variable Models. In Perpetual Motion: Travel Behaviour Research Opportunities and Application Challenges ( $\mathrm{H}$. Mahmassani, ed.), Elsevier Science, Amsterdam, Netherlands, 2002, pp. 431-470.

38. Morikawa, T., M. Ben-Akiva, and D. McFadden. Discrete Choice Models Incorporating Revealed Preferences and Psychometric Data. Econometric Models in Marketing, Advances in Econometrics (P. H. Franses and A. L. Montgomery, eds.), Elsevier, Amsterdam, Netherlands, 2002, pp. 29-55.

39. Walker, J., and M. Ben-Akiva. Generalized Random Utility Model. Mathematical Social Sciences, Vol. 43, No. 3, 2002, pp. 303-343.

40. Leclercq, L. Calibration of Flow-Density Relationships on Urban Streets. In Transportation Research Record: Journal of the Transportation Research Board, No. 1934. Transportation Research Board of the National Academies, Washington, D.C., 2005, pp. 226-234

41. Hausman, J. A. Specification Tests in Econometrics. Econometrica, Vol. 4, No. 6, 1978, pp. 251-271.

The opinions, findings, and conclusions or recommendations expressed in this publication are those of the authors and do not necessarily reflect the views of TfL.

The Traffic Flow Theory and Characteristics Committee peer-reviewed this paper 